gives a brief sketch of the conclusions that may be drawn from a study of the remains recently found by Prof. Petrie between Ballas and Naqâda. Towards the end of the sixth dynasty the Libyans, yielding to a migratory impulse, overran the western frontier and established themselves in Egypt, leaving a permanent record of their presence in the burying places and remains of villages which extend the whole length of the mountain chain from Siût to Gebelên. Prof. Maspero does not go so far as Prof. Petrie, who would regard the whole of the south of Egypt as having been wrested from the native kings by this "new race"; he does, however, conclude that these Libyan settlers were predominant throughout a considerable area on the left bank of the river, and that their influence was felt for more than a century. The pagination remains the same as that of the two earlier editions of the book.

The Local Distribution of Electric Power in Workshops, \& $\sigma^{\circ}$. By Ernest Kilburn Scott, A.I.E.E. Pp. 137 + viii. (London: Biggs and Co.)

THE advantages of electric transmission of power in factories and workshops are not so well known as they might be, or the electric driving of machinery would be more extensively adopted than it is. Wherever electric motors have been made to do duty in machine shops, complete success has been attained, but it is only in late years that engineers and proprietors of factories have learned to make use of electric driving to any great extent. Lately, however, this branch of electrical engineering has been coming to the front, and it promises to develop into the most important branch of electrical work, electric lighting not excepted,

The information brought together by Mr. Scott will show manufacturers what has been done, and what electric motors are capable of doing. The advantages of electric driving, both economically and commercially, are clearly pointed out, and detailed particulars of power required by various machines are given. The advantages and disadvantages of alternating currents from the point of view of power distribution in factories are discussed, and there are descriptions of the various points of a power installation, with examples of the most recent practice. The book is thus one which should be in the hands of all who are concerned with the applications of electricity to the machines and tools of workshops and factories.

Memory and its Cultivation. By F. W. Edridge-Green, M.D., F.R.C.S. (International Scientific Series.) Pp. 307. (London: Kegan Paul and Co., Ltd., I 897.)

DR. EDRIDGE-GREeN considers that the human mind is divisible into "ultimate faculties," a list of which he gives. Of these "ultimate faculties" some thirty-seven are assigned to this position with certainty. Dr. Green has no doubt whatever about their fitness to be considered "ultimate faculties," although amongst them are such qualities as Causality, Alimentiveness, and Inhabitiveness. Others there are, such as Vitativeness and Human Nature, whose position as ultimate faculties of the human mind is still sub judice. Dr. Green might, we think, have postponed the publication of this book until he had made up his mind about them. Part of the book is devoted to the description of a system of cultivating the memory; but there is the best possible evidence that either Dr. Green does not himself utilise this system, or the system is worthless. He would certainly never have published a work on psychology without acquainting himself with the present state of knowledge upon the subject. Yet he has forgotten the whole of his psychological studies as completely as if they had never existed. If his system were one for cultivating the art of forgetfulness, and were a perfect system, the result could not be more complete.

$$
\text { No. I } 470 \text {, vOL. } 57]
$$

Illusions and Hallucinations. By Edmund Parish. Pp. xiv + 390. (London: Walter Scott, Ltd., I897.)

THIS is a very thorough account of the subject, in fact it is, perhaps, for the series to which the book belongs, almost too thorough, and the general reader may find some difficulty in getting a clear account of the author's views out of the mass of detail. The conditions of fallacious perception are fully considered, and the general phenomena are referred to disturbed association. The author gives new definitions of illusion and hallucination, the former being supposed to depend on the suppression of certain processes which normally intervene between the immediate sensory change and the perception process, while hallucination is referred to forced association. These definitions have the advantage that they refer both phenomena to a common cause, i.e. to dissociation of centres normally acting together; but they are open to the objection that they are based on purely theoretical and uncertain views, and it would probably be better to retain the old definition depending on the existence or nonexistence of an external stimulus while recognising that there is no hard and fast line between the two conditions. There are two interesting chapters on the results of the international census of waking hallucinations: The author brings forward much evidence that the real nature of the "waking state" in most cases was one of abnormal dissociation. He criticises adversely the evidence for telepathy derived from the census, which was regarded as valid by the authors of the English Report. He brings forward from the Report itself evidence against this conclusion, and in regard to the supposed positive evidence, he lays great stress on the importance of similarity of association of ideas in the two cases. Among many other interesting points, only one can be mentioned here, viz. the criticism of the view that the negative hallucinations of hypnotism depend on suggested inattention. The author points out that an object may be made by suggestion to appear smaller and smaller, till it finally disappears. In this case, according to the theory, a phenomenon due to concentration or special direction of attention would be suddenly replaced by one due to lack of attention.

\section{Transactions of the Rochdale Literary and Scientific}

Society. Vol. v., I896-97. Pp. $90+$ xxii. (Rochdale : James Clegg, I897.)

Bx publishing the papers in this volume the Council of the Rochdale Literary and Scientific Society brings the work of the Society into prominence, and assists in making the objects of the meetings known to a wider circle. The volume is as interesting as its predecessors, and is a creditable addition to local literature and science. Among the papers contained in the volume is a chatty account of "Men and Manners in Manila," by Dr. A. Jefferson, an elementary description (with figures) of "Egyptian hieroglyphics, picture-writing, and the English -alphabet," by Mr. C. Heape, a brief note on some graphite and flint implements found in a neolithic store near Rough Hill, by Mr. W. H. Sutcliffe, and a paper on the geological history of the Cephalopoda, by Mr. Charles Wardingley.

We see from the report that a number of other papers, not included in the present volume, were read before the Society during the nineteenth session, and several very instructive lectures were delivered. The Society, appears, indeed, to be a centre of light and leading in Rochdale.

Les Constantes Physico-Chemiques. By D. Sidersky. Pp. 207. (Paris: Gauthier-Villars et Fils. Masson and $\mathrm{C}^{\mathrm{ie}}$.

M. SiDERSKy has already contributed a volume on polarisation and saccharimetry to the Aide-Mémoire series in which the present book appears. The constants herein described are dealt with in a similar manner; they 